\title{
Comparison of percutaneous intradiscal ozone injection with laser disc decompression in discogenic low back pain
}

This article was published in the following Dove Press journal: Journal of Pain Research

\author{
Poupak Rahimzadeh' \\ Farnad Imani' \\ Mohammad Ghahremani' \\ Seyed Hamid Reza Faiz ${ }^{2}$ \\ 'Pain Research Center, Iran University \\ of Medical Sciences, Tehran, Iran; \\ ${ }^{2}$ Anesthesiology Department, Iran \\ University of Medical Sciences, Tehran, \\ Iran
}

Correspondence: Poupak Rahimzadeh Pain Research Center, Rasoul Akram Hospital, Niayesh Ave, Sattarkhan St, Tehran 1916737183, Iran

Tel +989121064483

Fax +98 21 66509059

Email poupak_rah@hotmail.com
Background: Intervertebral disc herniation with the pressure on the surrounding neural structures is one of the most important causes of chronic low back pain, which sometimes leads to open surgery. Reducing the pressure inside the disc with intradiscal intervention such as laser irradiation or ozone injection is a minimally invasive method and an alternative to surgery with satisfactory results. These two methods were compared with each other in this research.

Patients and methods: In this clinical trial, 40 patients with back pain radiating to lower limb due to lumbar intervertebral disc herniation were selected. These patients were randomly divided into two equal groups for percutaneous intradiscal intervention. The Laser Disc Decompression Group (LDG) $(n=20)$ was exposed to $1500 \mathrm{~J}$ of laser irradiation into the disc center. In the Ozone Injection Group (OZG) patients $(\mathrm{n}=20), 6 \mathrm{~mL}$ of ozone $30 \mu \mathrm{g} / \mathrm{mL}$ was injected into the center of the disc. Considering the level of neural root involvement, both groups received $20 \mathrm{mg}$ of triamcinolone injection via transforaminal epidural. Patients were followed up for 12 months regarding score on visual analogue scale and life performance improvement based on Oswestry Disability Index (ODI) and satisfaction level.

Results: According to the results, no difference was found between the two groups for ODI variable before intervention, whereas OZG showed better ODI scores in the measured time intervals. In LDG, only a significant difference in terms of ODI score was found between the times of before surgery and the first month.

Conclusion: Intradiscal ozone injection could be an effective and cost-effective method for treatment of patients with discogenic back pain.

Keywords: low back pain, laser disc decompression, ozone injection, visual analogue scale, Oswestry Disability Index

\section{Introduction}

Chronic back pain (CBP) is one of the common causes of patients' admission to pain clinics, ${ }^{1}$ which usually do not show any recognizable problems on imaging and is attributed to muscle strain or ligament injuries. ${ }^{2}$ Degenerative changes in the disc wall and herniation of the disc core contents cause pressure effects on adjacent neural structures, leading to back pain, which sometimes radiates to lower limbs resulting in disability or deficit. Direct mechanical pressure and secondary inflammatory reactions induced by neural sensitivity are the main causes of pain. Medical treatment (nonsteroidal anti-inflammatory drugs [NSAIDs], neuromuscular blockers, etc.), physical therapy and rehabilitation are the primary treatment methods. In this regard, open surgery and resection of the material within a disc with reducing pressure effect imposed on neural structures is a common treatment 
approach. ${ }^{3,4}$ As alternatives for surgery, several minimally invasive methods have been introduced, which act by partial removal of the disc and reducing the pressure on the spinal cord and neural roots. Percutaneous intradiscal access with specific needles through skin and laser radiation performance, radiofrequency thermal lesioning, aspiration discectomy and ozone chemonucleolysis are among the developed alternative procedures introduced in recent decades. These methods that reduce the volume of disc contents and the pressure on surrounding tissues have gained an increased popularity. ${ }^{4,5}$ Ozone reduces disc volume by oxidation of the core proteins of nucleus pulposus (NP). ${ }^{6,7}$ Similar to radiofrequency, laser acts through heating that results in the evaporation of the fluid within the NP, thus reducing the inflammatory mediators and nociceptors. ${ }^{8}$ In our study, patients with radicular back pain were treated using intradiscal laser decompression or ozone injection, and patients were compared in terms of pain relief and improved performance.

\section{Patients and methods}

This randomized double-blind clinical trial was conducted among patients admitted to pain clinic of an academic general hospital in Tehran, Iran, due to discogenic back pain. The study was approved by the Ethics Committee of Iran University of Medical Sciences with the registry number IR.IUMS. REC.1395.27280 and by the Clinical Trial Center with the registry number IRCT2016011910599N7. The sample size was calculated to be 20 people for each group considering the previous studies with alpha $=0.05$, power of $90 \%$ and $d=1.2$. Adequate explanations of the study method were provided to the patients from whom written informed consent was obtained. The patients were randomly assigned into two groups: percutaneous intradiscal Laser Decompression Group (LDG) and Ozone Injection Group (OZG). Sampling was performed based on block randomization. Assuming that two methods of $\mathrm{A}$ and $\mathrm{B}$ were being tested, 15 blocks were selected by random numbers. The patients were unaware of their group assignment.
The inclusion criteria of the study were as follows: the American Anesthesiology Association class 1-2; aged between 20 and 70 years; having at least 8 weeks of back pain symptoms; and pressure on the spinal cord neural roots. Intervertebral disc herniation was diagnosed in the MRI as the cause of pain congruous with the neurologic level. All patients underwent clinical and radiological assessment by a neurologist. Those patients with partial motor weakness were referred for neurosurgical consultation to confirm the deficit. All patients had received conservative therapy (physiotherapy and/or NSAIDs and/or intramuscular steroids) for 4-6 weeks with no or poor clinical improvement.

Exclusion criteria of study were patient dissatisfaction, cauda equina syndrome, sequestrated disc contents, any motor deficit, involvement of more than two discs and history of G6PD deficiency in patients who were candidates to receive intradiscal ozone injection, pregnancy, recorded allergy to proposed drugs, major neurologic deficits, hemorrhagic diathesis, suspected spondylodiscitis and previous spine surgery.

Upon entrance to the operating room, standard monitoring was performed and the level of intervention was identified in the prone position. The sedative drug was injected; after surgical prep and drep and skin local anesthesia, a Chiba needle ( $15 \mathrm{~cm}, \mathrm{G} 20)$ was entered in the fluoroscopic oblique view of $35-40^{\circ}$, anterior to the superior articular process of the desired level guided under "tunnel view" and directed by oblique, lateral and AP view toward the NP. After injecting radiopaque contrast medium (Omnipaque 240) and checking by $\mathrm{C}$-arm view, the patients in the LDG received laser radiation by insertion of laser probe into the disc (Diode laser; Biolas, Ankara, Turkey) with a wavelength of 1470 $\mathrm{nm}$ operating in the $0.75-12 \mathrm{~W}$ range power, up to $1500 \mathrm{~J}$, 0.50 second pulsed, 1.5 second pause (total 2 seconds). In the OZG, $6 \mathrm{~mL}$ of $30 \mu \mathrm{gr} / \mathrm{mL}$ ozone was injected into the NP. In both groups, at the involved level, a transforaminal epidural block under $15-25^{\circ}$ fluoroscopic view was performed with
A

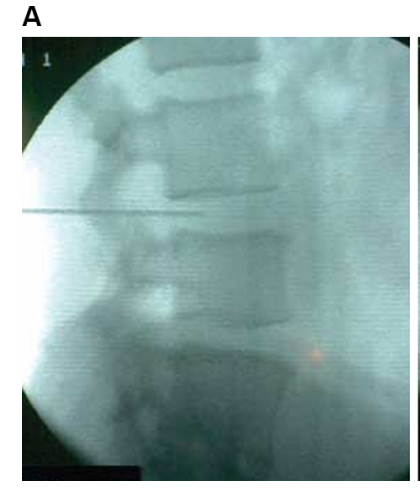

B

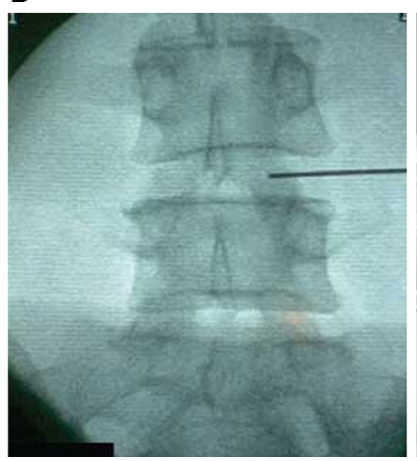

C

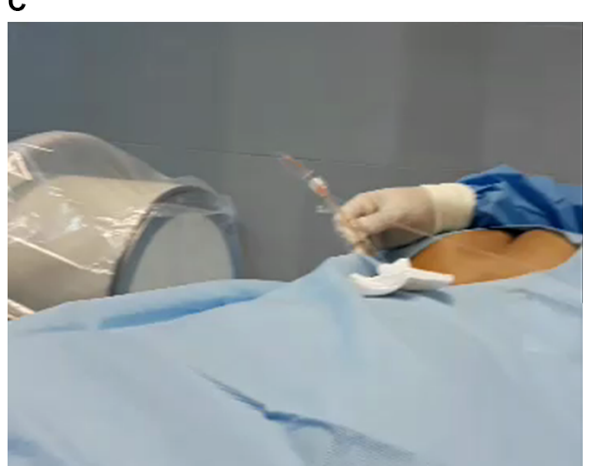

Figure I Lateral (A) and anteroposterior (B) X-ray view and laser probe insertion (C) for percutaneous intradiscal laser decompression. 
the injection of $5 \mathrm{~mL}$ Marcaine $0.2 \%$ and $20 \mathrm{mg}$ triamcinolone. Figure 1 shows lateral and anteroposterior X-ray view of percutaneous intradiscal laser decompression.

Finally, patients were monitored for 6 hours in the recovery room before they were discharged. The patients were trained to record the pain score, functional disability and any possible complications or limitations. The follow-up period in both groups was considered 12 months and the pain level was evaluated based on the visual analogue scale and Oswestry Disability Index (ODI) ${ }^{9}$ by Fairbank and Pynsent who were blinded to the groups. VAS was measured by a $10 \mathrm{~cm}$ length horizontal bar, so that the patient would indicate his/her pain on the axis from zero to $10 \mathrm{~cm}$. The measured interval times were before intervention and 1, 3, 6 and 12 months after performing the intervention. The investigator called the patients and asked them for follow-up visits. All data were recorded in questionnaire forms. Other demographic information and any possible complications were recorded based on the questionnaire.

The Interclass Correlation Coefficient of this scale was reported to be 0.91 . In order to measure the disability of the patients, a revised functional disability assessment questionnaire for the patients with back pain was used, measuring both chronic and acute low back pain. It included 10 questions with 6 options per question (scored from 0 to 5). Choosing of each option could measure the level of patient's ability in different aspects such as pain tolerance, performing personal activities, lifting up objects, sleeping, sitting, standing, walking, social communication and traveling. The total score of 10 parts was multiplied by 2 and scored from 0 to 100 . Scoring was as follows: scores of $0-20=$ minimal disability, $21-40=$ moderate disability, $41-60=$ severe disability, $61-80=$ crippling back pain, $81-100=$ these patients are either bed bound or have an exaggeration of their symptoms. Satisfaction score was measured as very good, good, low satisfaction and dissatisfaction.

After data collection, data analysis was conducted by a statistician using SPSS version 18, and significance level of the tests ( $p$-value) was considered to be 0.05 . The results were stated as mean \pm SD. To compare the mean pain before and after the intervention, paired $t$-test or a non-parametric test was used, and to compare the means, $t$-test or its equivalent non-parametric test, namely Mann-Whitney, was used. Chisquare test was used to compare qualitative data.

\section{Results}

Comparison of the demographic characteristics of the patients showed no statistically significant difference in sex, height, weight, body mass index, age, and disease duration and level among the groups $(p>0.05)$.

The frequency and percentage of satisfaction showed that there was no significant difference in the satisfaction level of the patients between two groups $(p=0.6)$.

After performing the procedure, there was no significant difference in pain in terms of VAS in measured intervals in each group $(p=0.8)$. The two groups did not have a statistically significant difference in pain as well $(p=0.1)$ (Table 1).

In this test, VAS of each member of the group was compared with the previous score. Only the mean of the pain score before surgery and 1 month after that was statistically different and showed a significant decline, but no significant difference was found in the other months (Table 2).

It was found that the ODI variable was significantly different in measured time intervals $(p=0.04)$, and a significant difference was observed between the two groups $(p=0.02)$.

Based on the obtained $p$-value, the ODI variable in the two groups was not significantly different before surgery and after the first month, whereas in the third, sixth and 12th months, the two groups showed a significant difference in terms of ODI score $(p<0.05)$ plus the fact that the OZG showed better

Table I Paired comparison of VAS scale in measured times

\begin{tabular}{llll}
\hline $\begin{array}{l}\text { Measured } \\
\text { times }\end{array}$ & Group & Mean VAS & p-value \\
\hline Before surgery & OZG & 79.00 & 1.0 \\
& LDG & 79.00 & \\
First month & OZG & 31.50 & 0.2 \\
& LDG & 37.50 & \\
Third month & OZG & 25.50 & 0.2 \\
& LDG & 31.50 & \\
Sixth month & OZG & 28.50 & 0.2 \\
& LDG & 38.50 & \\
Twelfth month & OZG & 30.00 & 0.4 \\
& LDG & 35.50 & \\
\hline
\end{tabular}

Abbreviations: VAS, visual analogue scale; OZG, Ozone Injection Group; LDG, Laser Decompression Group.

Table 2 Comparison of VAS at different time intervals

\begin{tabular}{llll}
\hline $\boldsymbol{p}$-values & $\begin{array}{l}\text { LDG } \\
\boldsymbol{p} \text {-value }\end{array}$ & $\begin{array}{l}\text { OZG } \\
\boldsymbol{p} \text {-value }\end{array}$ & $\begin{array}{l}\text { VAS difference } \\
\text { with the previous } \\
\text { measured time }\end{array}$ \\
\hline$p<0.05$ & 0.001 & 0.001 & VAS0-VASI \\
$p>0.05$ & 0.2 & 0.1 & VASI-VAS3 \\
$p>0.05$ & 0.07 & 0.3 & VAS3-VAS6 \\
$p>0.05$ & 0.1 & 0.2 & VAS6-VASI2 \\
\hline
\end{tabular}

Abbreviations: VAS, visual analogue scale; LDG, Laser Decompression Group; OZG, Ozone Injection Group. 
Table 3 ODI means and differences at measured time intervals

\begin{tabular}{llllllll}
\hline Group & $\begin{array}{l}\text { Before } \\
\text { surgery }\end{array}$ & $\begin{array}{l}\text { First } \\
\text { month }\end{array}$ & $\begin{array}{l}\text { Third } \\
\text { month }\end{array}$ & $\begin{array}{l}\text { Sixth } \\
\text { month }\end{array}$ & $\begin{array}{l}\text { Twelfth } \\
\text { month }\end{array}$ & $\begin{array}{l}\text { p-value } \\
\text { Percentage of } \\
\text { reduction in ODI }\end{array}$ \\
\hline OZG & 62.70 & 33.65 & 23.40 & 23.10 & 25.10 & 0.04 & $60 \%$ \\
LDG & 67.35 & 39.00 & 34.46 & 37.25 & 37.15 & $50 \%$ & \\
P-value & 0.2 & 0.2 & 0.02 & 0.02 & 0.05 & & 0.02 \\
OZG and & Difference between two groups & & & & \\
LDG & & & & & &
\end{tabular}

Abbreviations: ODI, Oswestry Disability Index; OZG, Ozone Injection Group; LDG, Laser Decompression Group.

Table 4 Comparison of ODI at different time intervals

\begin{tabular}{lll}
\hline $\begin{array}{l}\text { LDG } \\
\boldsymbol{p} \text {-value }\end{array}$ & $\begin{array}{l}\text { OZG } \\
\boldsymbol{p} \text {-value }\end{array}$ & $\begin{array}{l}\text { Comparison of ODI } \\
\text { at different time } \\
\text { intervals }\end{array}$ \\
\hline 0.001 & 0.001 & ODI0-ODII \\
0.07 & 0.003 & ODII-ODI3 \\
0.3 & 0.8 & ODI3-ODI6 \\
0.9 & 0.02 & ODI6-ODII2 \\
\hline
\end{tabular}

Abbreviations: ODI, Oswestry Disability Index; LDG, Laser Decompression Group; OZG, Ozone Injection Group.

results than the LDG, and the ODI reduction percentage was $60 \%$ in OZG (Table 3).

The OZG results showed that there were significant differences in terms of ODI scores between all the measured times with the previous one except between the third and sixth months.

In the LDG, a significant difference was found only between before the surgery and the first month, but no significant relationship was found between other times. (Table 4)

No complications were reported for either group.

\section{Discussion}

Lumbar disc herniation (LDH) is the most common cause of CBP and vertebral surgery. Surgery is still considered as a standard therapeutic method for affected patients. ${ }^{3,4}$ Less invasive interventions such as percutaneous laser disc decompression (PLDD), intradiscal injection of ozone or other drugs, and endoscopic surgery have been considered to be highly promising. These treatments have yielded different results in short- and long-term follow-up. Considering the faster recovery and lower costs of these methods, it is believed that less invasive approaches would be welcomed more in the furure. ${ }^{10-12}$ We compared two percutaneous techniques in this study and found good results with both, but better outcomes with ozone injection.
Intradiscal injection of ozone is recommended as a costeffective procedure for LDH treatment with as low as $0.1 \%$ risk; moreover, the intradiscal ozone injection along with periganglionic injection of a corticosteroid has produced a cumulative effect enhancing the overall outcome of this treatment. ${ }^{13}$ We found a similar result with the abovementioned study in terms of pain scores and functional improvement by performing transforaminal injection in the current study.

Another study was conducted among patients with back pain due to $\mathrm{LDH}$ with pressure on neural roots with injection of $4 \mathrm{~mL}$ of intradiscal ozone and $8 \mathrm{~mL}$ of preganglionic ozone. Steroid and bupivacaine were injected over the involved nerve root in $50 \%$ of them. After 6 months of evaluation, more than $70 \%$ recovery was observed; however, in the group with ganglionic steroid injection a better result was observed. ${ }^{6}$ In our study, steroid injection was performed in both groups; $\geq 50 \%$ reduction in ODI score for both groups was observed. This showed that associated transforaminal administration of corticosteroids had anti-inflammatory effect, which may enhance the anti-inflammatory effects of ozone as well, plus the fact that acceptable LDG scores may be partly due to injected steroid.

Ozone injection under the CT guidance was performed in other study and the outcome was evaluated for 1 year. $^{7}$ The success rate of the therapeutic intervention was $75 \%-80 \%$, which was excellent considering the low cost and significant effectiveness. ${ }^{7}$ The results of ozone therapy in patients with LDH was evaluated in another study; a statistically significant reduction in all scores was found. Effectiveness and safety of this method were similar to disc surgery, but its complications were much less $(<0.1 \%)$ in addition to a shorter recovery time. ${ }^{14}$ In the current study, $60 \%$ improvement was observed in the OZG with no reported complications with a rapid discharge from hospital, which was 6 hours in our study. During the 1-year follow-up of our study, there was no need for open discectomy, which is very promising. 
Reducing the pressure inside the disc by laser radiation through the needle located at the center of the disc or PLDD is considered as another treatment method. One study with mean follow-up time of 42 months compared the results of PLDD at different levels, $12.7 \%$ of the patients underwent microsurgical open discectomy after PLDD. ${ }^{12}$ We did not find any need for open discectomy during the 1-year followup in both groups. Studies showed that while open surgery is the golden standard of treatment for LDH, PLDD is as effective as open surgery with shorter rehabilitation period, fewer complications and lower costs. Level II-2 of evidence was found for PLDD for short- and long-term pain relief. In one study with 2-year follow-up, the clinical effectiveness of PLDD compared to conventional surgery was evaluated and similar outcomes were found for both ${ }^{15-17}$ In another study, Nd.YAG laser was used and follow-up for 3 years was performed. In these patients, the pain gradually decreased over the course of 3 months and the patients' function improved in everyday life. ${ }^{8}$ In our study, the LDG showed a significant ODI improvement up to 1 month after the procedure, while ODI trend for OZG sustained a downward slope up to 3 months, which was promising. ODI variable was significantly decreased in measured time intervals, with a significant difference between the two groups, which showed better results in the OZG.

The anti-inflammatory effect of the concomitant transforaminal epidural injection is important in pain control outcome of our patients as well. In the OZG, this antiinflammatory action is even more apparent considering that all selected patients had previously undergone prolonged medical management with no clinical benefit. Moreover, pain relief can be accompanied by a shrinkage or disappearance of the bulging herniated disc responsible for nerve root compression, which has been evaluated in studies via MRI checking with no acceleration of the disc degeneration process in long-term follow-up. ${ }^{17-21}$

In the current study, better improvement in ODI and VAS scores was observed in the OZG compared with the LDG. Considering the lower costs of OZG, we concluded that it could be considered as a reliable alternative for laser. Less success rate in OZG compared with the previously done studies may be related to lower sample size and need more evaluation time. For the LDG population, lower reduction in ODI could be related to the fact that a disc that contains less fluid will likely respond less to laser energy being applied to vaporize the NP; hence, PLDD treatment is likely to be more effective in vaporizing fresh herniated discs. So, we recommend further and multi-centric studies with larger and better selected sample sizes and longer duration of evaluation.

Finally, our study had some limitations such as lack of a control group receiving placebo; lack of morphological assessment of disc and surrounding structures; lack of MRI control; small sample size; and limited timeframe for patients' assessment.

\section{Conclusion}

This first randomized controlled trial comparing PLDD and ozone discolysis demonstrated that intradiscal ozone injection could be an effective and cost-effective method for the treatment of the patients with discogenic back pain over a 1-year follow-up period.

\section{Acknowledgment}

The authors would like to thank Rasoul Akram Hospital Clinical Research Development Center, Iran University of Medical Sciences for technically supporting the implementation of the project.

\section{Author contributions}

All authors contributed toward data analysis, drafting and revising the paper and agree to be accountable for all aspects of the work.

\section{Disclosure}

The authors report no conflicts of interest in this work.

\section{References}

1. Walker BF. The prevalence of low back pain: a systematic review of the literature from 1966 to 1998. J Spinal Disord. 2000;13(3):205-217.

2. Setchell J, Costa N, Ferreira M, Makovey J, Nielsen M, Hodges PW. Individuals' explanations for their persistent or recurrent low back pain: a cross-sectional survey. BMC Musculoskelet Disord. 2017;18(1):466.

3. Manchikanti L, Benyamin R, Helm S, Hirsch JA. Evidence-based medicine, systematic reviews, and guidelines in interventional pain management: part 3: systematic reviews and meta-analyses of randomized trials. Pain Physician. 2009;12(1):35-72.

4. Andreula C. Percutaneous disc treatments. Neuroradiol J. 2009;22(1):141-143.

5. Lu Y, Guzman JZ, Purmessur D, et al. Nonoperative management of discogenic back pain: a systematic review. Spine (Phila Pa 1976). 2014;39(16):1314-1324.

6. Andreula CF, Simonetti L, De Santis F, Agati R, Ricci R, Leonardi M. Minimally invasive oxygen-ozone therapy for lumbar disk herniation. AJNR Am J Neuroradiol. 2003;24(5):996-1000.

7. Muto M, Ambrosanio G, Guarnieri G, et al. Low back pain and sciatica: treatment with intradiscal-intraforaminal O(2)-O (3) injection. Our experience. Radiol Med. 2008;113(5):695-706

8. Ren L, Guo H, Zhang T, Han Z, Zhang L, Zeng Y. Efficacy evaluation of percutaneous laser disc decompression in the treatment of lumbar disc herniation. Photomed Laser Surg. 2013;31(4):174-178. 
9. Fairbank JC, Pynsent PB. The Oswestry Disability Index. Spine (Phila Pa 1976). 2000;25(22):2940-2952; discussion 2952.

10. Brouwer PA, Peul WC, Brand R, et al. Effectiveness of percutaneous laser disc decompression versus conventional open discectomy in the treatment of lumbar disc herniation; design of a prospective randomized controlled trial. BMC Musculoskelet Disord. 2009;10:49.

11. Zhang Y, Ma Y, Jiang J, Ding T, Wang J. Treatment of the lumbar disc herniation with intradiscal and intraforaminal injection of oxygenozone. J Back Musculoskelet Rehabil. 2013;26(3):317-322.

12. Erbas YC, Pusat S, Erdogan E. Percutaneous laser disc decompression: retrospective analysis of 197 cases and review of the literature. Turk Neurosurg. 2015;25(5):766-770.

13. Giurazza F, Guarnieri G, Murphy KJ, Muto M. Intradiscal $\mathrm{O}_{2} \mathrm{O}_{3}$ : rationale, injection technique, short- and long-term outcomes for the treatment of low back pain due to disc herniation. Can Assoc Radiol J. 2017;68(2):171-177.

14. Steppan J, Meaders T, Muto M, Murphy KJ. A metaanalysis of the effectiveness and safety of ozone treatments for herniated lumbar discs. J Vasc Interv Radiol. 2010;21(4):534-548.

15. Moon BJ, Lee HY, Kim KN, et al. Experimental evaluation of percutaneous lumbar laser disc decompression using a $1414 \mathrm{~nm}$ Nd: YAG laser. Pain Physician. 2015;18(6):E1091-E1099.
16. Singh V, Manchikanti L, Benyamin RM, Helm S, Hirsch JA. Percutaneous lumbar laser disc decompression: a systematic review of current evidence. Pain Physician. 2009;12(3):573-588.

17. Brouwer PA, Brand R, van den Akker-van Marle ME, et al. Percutaneous laser disc decompression versus conventional microdiscectomy for patients with sciatica: two-year results of a randomised controlled trial. Interv Neuroradiol. 2017;23(3):313-324.

18. Imani F, Rahimzadeh P. Interventional pain management according to evidence-based medicine. Anesth Pain Med. 2012;1(4):235-236.

19. Dall'Olio M, Princiotta C, Cirillo L, et al. Oxygen-ozone therapy for herniated lumbar disc in patients with subacute partial motor weakness due to nerve root compression. Interv Neuroradiol. 2014;20(5): 547-554.

20. Magalhaes FN, Dotta L, Sasse A, Teixera MJ, Fonoff ET. Ozone therapy as a treatment for low back pain secondary to herniated disc: a systematic review and meta-analysis of randomized controlled trials. Pain Physician. 2012;15(2):E115-E129.

21. Bruno F, Smaldone F, Varrassi M, et al. MRI findings in lumbar spine following $\mathrm{O}_{2}-\mathrm{O}_{3}$ chemiodiscolysis: a long-term follow-up. Interv Neuroradiol. 2017;23(4):444-450.
Journal of Pain Research

\section{Publish your work in this journal}

The Journal of Pain Research is an international, peer reviewed, open access, online journal that welcomes laboratory and clinical findings in the fields of pain research and the prevention and management of pain. Original research, reviews, symposium reports, hypothesis formation and commentaries are all considered for publication.

\section{Dovepress}

The manuscript management system is completely online and includes a very quick and fair peer-review system, which is all easy to use. Visit http://www.dovepress.com/testimonials.php to read real quotes from published authors. 